\title{
SEUCHEN
}

LND

\section{ANSTECKENDE KRANKHEITEN}

\author{
DER HAUSSÄLGETHIERE.
}





\section{ALLGEMEINE LEHRE}

DER

\section{SEUCHEN}

UND

\section{ANSTECKENDEN KRANKHEITEN \\ DEl:}

\section{HAUŚSÄUGETHIERE.}

\section{VORLESUNGEN}

MIT ERGÄNZENDEN UND RECHTFERTIGENDEN BEILAGEN.

$$
\text { voN }
$$

\section{CHRISTIAN JOSEPH FUCHS,}

TROFESSOR DER VETERINARR-MEDICIN AN DER UNIVERSITÄT KEIDEI,BERG.

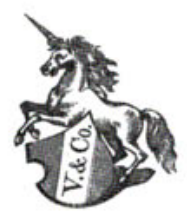

LEIPZIG,

VERLAG VON VEIT \& COMP.

1862 . 
